\title{
Factors Influencing Number of Physiotherapy Treatment Sessions for Patients with Low Back Pain
}

\author{
Odebiyi D.O., Aweto H.A., Igbari T.O., Tella B.A. \\ Department of Physiotherapy, Faculty of Clinical Sciences, College of Medicine, University of Lagos, Lagos, Nigeria \\ Correspondence \\ Daniel O. Odebiyi; PM B 12003, Idi-Araba Surulere, Lagos; E-mail: femiodebiyi@yahoo.com
}

\begin{abstract}
SUMMARY
Little is known about the influence of physiotherapists' characteristics and treatment modalities on the number of treatment sessions in Nigeria. This study was designed to evaluate the factors influencing the number of treatment sessions for patients with low back pain (LBP).

Three hundred and eleven practising physiotherapists based in Nigeria participated in this study $(77.8 \%$ response rate). They were required to complete a 31-item closed-ended questionnaire, which collected information on demographic data, work experience and treatment activities. Data was represented using bar charts, frequency and percentage. Chi-square was used to determine significant difference at $\mathrm{p}=0.05$. About $114(38.10 \%)$ of the respondents employed 10 treatment sessions in the treatment of patients with LBP. Gender, age, areas of interest and educational attainment influenced the number of treatment sessions $(p<0.05)$. Older male respondents, with higher educational attainment, especially those who are specialized in orthopaedics had fewer treatment sessions with their patients. However, working experience, acquisition of additional training (through continuous professional education) and types of treatment modalities did not have any significant relationship with number of treatment sessions $(\mathrm{p}>0.05)$.

The average number of treatment sessions administered to patients with LBP before they are discharged in Nigeria is ten sessions. This was influenced by gender, age, areas of interest and educational attainment. There was a general consensus that a treatment guideline is needed for proper management of patients with LBP.
\end{abstract}

KEYWORDS: LBP, treatment sessions, physiotherapist's characteristics, Nigeria

\section{INTRODUCTION}

Low back pain (LBP) is the most common form of back pain. It may be restricted to the back areas (low-back, midback and high-back) or may radiate down one or both legs (Goldestein, 2002), and has been defined as pain or discomfort felt in the area bounded superiorly by T12 and inferiorly by the buttock creases (Watson et al, 2005). Low back pain is the most common cause of absence from work for both men and women between 20 and 65 years of age (Walsh et al, 1990). In West Africa, four out of every five adults has had LBP. It is one of the most common conditions managed by physiotherapists in out-patient clinics (Levine, 1992; Jette et al, 1994). Thus, physiotherapy is an important treatment approach used in the management of patients with LBP. The number of physiotherapy treatment sessions employed in the treatment of patients with LBP has been reported to be influenced by a number of factors (Stéphane et al, 2005). Physiotherapy treatment sessions (PTS) refer to the period of time when physiotherapy care is applied to cure/heal conditions/ injuries or ease symptoms (Hornby, 2000).

Swinkles et al (2005) reported that most of the factors that influence the physiotherapy treatment sessions (PTS) of patients with LBP arose from the patients. There is little 
information about the factors that influence the treatment sessions of patients with LBP from the physiotherapist's point of view. Some of the factors that influence the PTS of patients with LBP may arise from the physiotherapists themselves, as certain characteristics of the physiotherapists have also been reported to influence PTS (Jette et al, 1994; Hendriks et al., 2000). Therefore, an in-depth understanding of the factors that can influence the PTS of patients with LBP will increase the transparency of care and provide novel insights into the quality of care provided by physiotherapists (Swinkels et al, 2005).

Factors like the physiotherapist's sex, age, type of management given to the patient, additional training in LBP management (continuous professional development) and specialization in manipulative therapy have been reported to influence the number of PTS of patients with LBP (Jette et al, 1994; Hendriks et al., 2000; Swinkels et al., 2005). According to Swinkels et al (2005), female and older physiotherapists employed fewer treatment sessions in the treatment of patients with LBP than male and younger physiotherapists. Also, patients treated by physiotherapists with specialization in manual therapy and additional training in LBP (continuous professional development) received 1.4 and 1.5 sessions, respectively, less than patients treated by other physiotherapists (Swinkels et al, 2005). There is evidence that some interventions are preferable to others (Jette et al, 1994), thus, the type of management given to the patient can also be an important factor that can affect the number of PTS received by patients with LBP.

The high prevalence of LBP and its burden on the society has been a source of great concern for health care providers, especially physiotherapists, especially the number of treatment sessions that is ideal for patients with LBP. It is believed that this will improve the quality of treatment administered to patients, thereby facilitating full rehabilitation (Swinkels et al, 2005). This study was therefore designed to evaluate the influence of physiotherapists' characteristics (age, gender, working experience and educational attainment) and the types of treatment modalities used in the management of LBP on the number of physiotherapy treatment sessions for patients with LBP.

\section{MATERIALS AND METHODS}

\section{Participants}

A total of 311 practising physiotherapists (181 males and 120 females) participated in this study. They were recruited from the teaching hospitals, the federal medical centres
(FMC), specialist hospitals, general hospitals, rehabilitation centres, sport centres and private physiotherapy clinics in Nigeria.

\section{Questionnaire Design}

The questionnaire was titled Physiotherapy Treatment Session (PT-TS) Questionnaire. The initial draft of the questionnaire was adopted from previous studies that are related to the present study (Swinkels et al, 2005; Poitras et $\mathrm{al}, 2005)$. This served as the working document used by a six-man focus group to develop the final draft. The questionnaire consisted of 31 open-ended questions and was divided into three sections. Section A was used to obtain information on the demographic data of the participants, which included age, sex, marital status, highest level of qualification, school (university) attended and year of graduation. Section B sought information on the working experience of the physiotherapist, while Section $C$ was used to obtain information on the treatment preferences of the physiotherapist. Prior to distribution, the questionnaire was sent to two physiotherapy educators at the College of Medicine, University of Lagos, and to one clinician at the Lagos University Teaching Hospital; all being experts in questionnaire design, in order to determine its validity. Corrections were made according to their inputs.

\section{Administration of Questionnaire}

Prior to the administration of the questionnaire, approval was sought and obtained from the Research and Ethics Committee of the Lagos University Teaching Hospital, Lagos, Nigeria. Copies of the questionnaire were then distributed on a one-on-one basis to practising physiotherapists from hospitals located in the western part of Nigeria, and by speed post to physiotherapists in the other parts of Nigeria. Participants for this study were selected from hospitals from the six geo-political zones in Nigeria. The aims and objectives of the study were clearly explained in a cover note attached to each copy of the questionnaire, in order to seek their consent.

\section{Data Analysis}

Data collected were analysed using the SPSS version 17. The results were presented using descriptive statistics: mean, standard deviation, frequency, percentages, pie charts and bar charts. Chi square was used to determine significant difference at $\mathrm{p}<0.05$. 


\section{RESULTS}

Three hundred and eleven copies of the questionnaire were returned out of the 400 copies distributed, giving a response rate of $77.8 \%$. About $309(99.4 \%)$ of the respondents treated patients with LBP regularly, with 141 (45.6\%) adopting treatment durations of between 30 and 45 minutes. One hundred and seventy-seven $(56.9 \%)$ of the respondents were in the junior cadre (figure 1). The number of sessions employed by $114(36.7 \%)$ of the respondents in the treatment of patients with LBP was 10 (figure 2).

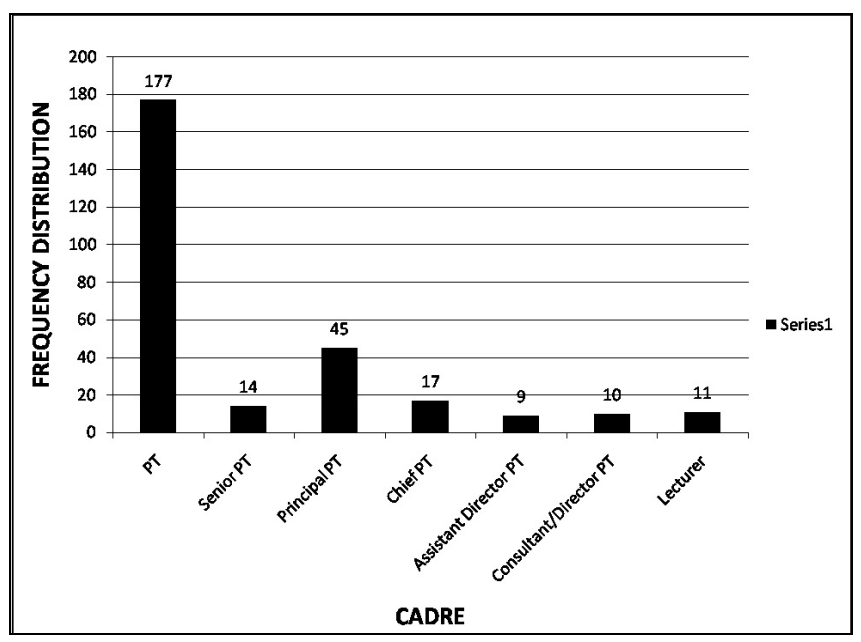

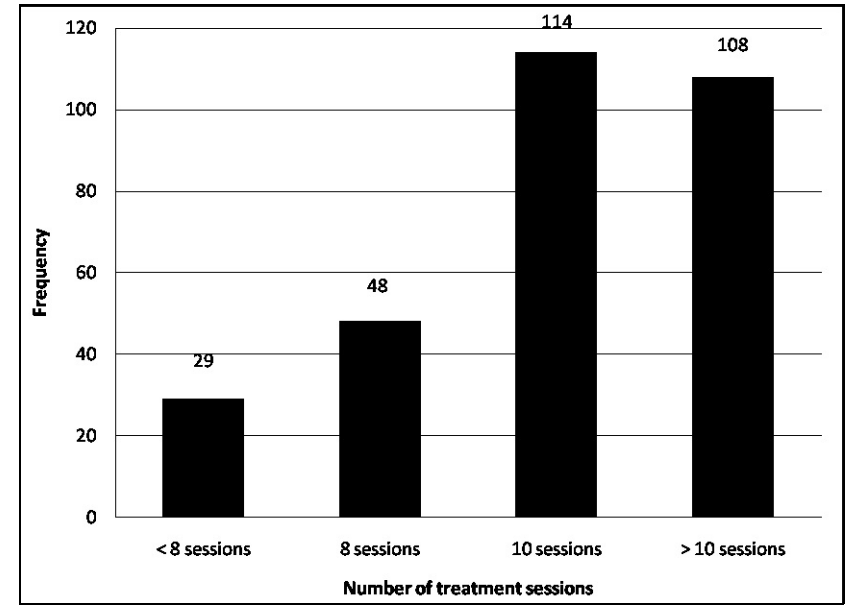

Figure 2. Frequency Distribution of the Number of Treatment Sessions

The chi-square analysis showed that there was a significant relationship between PTS, and the age $(\mathrm{p}=0.01)$, areas of interest $(p<001)$, gender $(p=0.03)$, and educational attainment $(\mathrm{p}<001)$ of the respondents (table 1$)$. There was no significant relationship between PTS and working experience, additional training (on the management of LBP), choice of modality and use of outcome measures (table 2).

Figure 1. Frequency Distribution of Respondents Cadre

Table 1. Chi-square Analysis of the Relationship Between Treatment Sessions, and Respondents' Age, Areas of Interest, Gender and Educational Attainment

\begin{tabular}{|c|c|c|c|c|c|c|c|c|c|c|}
\hline \multirow[t]{2}{*}{ Variable } & \multicolumn{2}{|c|}{$<8$ sessions } & \multicolumn{2}{|c|}{8 sessions } & \multicolumn{2}{|c|}{10 sessions } & \multicolumn{2}{|c|}{$>10$ sessions } & \multirow[t]{2}{*}{$\mathrm{X}^{2}$} & \multirow{2}{*}{$\begin{array}{l}P \\
\text { value }\end{array}$} \\
\hline & $\mathrm{n}$ & $\%$ & $\mathrm{n}$ & $\%$ & $\mathrm{n}$ & $\%$ & $\mathrm{n}$ & $\%$ & & \\
\hline \multicolumn{11}{|l|}{ Age (years) } \\
\hline $20-24$ & 1 & 5.00 & 2 & 10.00 & 6 & 30.00 & 11 & 55.00 & \multirow{7}{*}{43.57} & \multirow{7}{*}{0.01} \\
\hline $25-29$ & 12 & 13.00 & 18 & 19.60 & 31 & 33.70 & 31 & 33.70 & & \\
\hline $30-34$ & 5 & 6.30 & 18 & 22.80 & 29 & 36.70 & 27 & 34.20 & & \\
\hline $35-39$ & 1 & 2.00 & 4 & 7.80 & 28 & 54.90 & 18 & 35.30 & & \\
\hline $40-44$ & 6 & 14.30 & 6 & 14.30 & 13 & 31.00 & 17 & 40.50 & & \\
\hline$>44$ & 4 & 26.66 & 0 & 0.00 & 7 & 46.66 & 4 & 26.66 & & \\
\hline Total & 29 & 9.70 & 48 & 16.10 & 114 & 38.10 & 108 & 36.10 & & \\
\hline \multicolumn{11}{|l|}{ Areas of Interest } \\
\hline Neurology & 9 & 14.28 & 12 & 19.04 & 20 & 31.74 & 22 & 34.92 & \multirow{7}{*}{98.61} & \multirow{7}{*}{0.00} \\
\hline Medicine & 0 & 0.00 & 4 & 20.00 & 6 & 30.00 & 10 & 50.00 & & \\
\hline Orthop/Sport & 15 & 10.27 & 17 & 11.64 & 63 & 43.15 & 51 & 34.93 & & \\
\hline Cardiopulmonary & 4 & 20.00 & 3 & 15.00 & 8 & 40.00 & 5 & 25.00 & & \\
\hline Paediatrics & 1 & 3.44 & 8 & 27.58 & 11 & 37.93 & 9 & 31.03 & & \\
\hline Others & 0 & 0.00 & 4 & 20.00 & 5 & 25.00 & 11 & 55.00 & & \\
\hline Total & 29 & 9.70 & 48 & 16.10 & 113 & 37.91 & 108 & 36.24 & & \\
\hline \multicolumn{11}{|l|}{ Gender } \\
\hline Male (181) & 25 & 13.80 & 28 & 15.50 & 68 & 37.6 & 60 & 33.10 & \multirow[b]{2}{*}{9.26} & \multirow[b]{2}{*}{0.03} \\
\hline Female (120) & 4 & 3.40 & 20 & 16.90 & 46 & 39.00 & 48 & 40.70 & & \\
\hline \multicolumn{11}{|l|}{ Educational } \\
\hline First degree & 18 & 8.86 & 36 & 17.73 & 63 & 31.03 & 78 & 38.12 & \multirow{4}{*}{33.22} & \multirow{4}{*}{0.00} \\
\hline Master's & 8 & 8.08 & 11 & 11.11 & 48 & 48.48 & 28 & 28.28 & & \\
\hline $\mathrm{PhD}$ & 4 & 50.00 & 1 & 12.50 & 1 & 12.50 & 2 & 25.00 & & \\
\hline Total & 29 & 9.70 & 48 & 16.10 & 112 & 37.71 & 108 & 36.10 & & \\
\hline
\end{tabular}


Odebiyi, Aweto, Igbari, Tella

Table 2. Chi-square Analysis of the Relationship Between Treatment Sessions, and Working Experience, Additional Training (on the management of LBP)

\begin{tabular}{|c|c|c|c|c|c|c|c|c|c|c|}
\hline \multirow[t]{2}{*}{ Variable } & \multicolumn{2}{|c|}{$<8$ sessions } & \multicolumn{2}{|c|}{8 sessions } & \multicolumn{2}{|c|}{10 sessions } & \multicolumn{2}{|c|}{$>10$ sessions } & \multirow[t]{2}{*}{$\mathrm{X}^{2}$} & \multirow[t]{2}{*}{$\mathrm{P}$ value } \\
\hline & $\mathrm{n}$ & $\%$ & $\mathrm{n}$ & $\%$ & $\mathrm{n}$ & $\%$ & $\mathrm{n}$ & $\%$ & & \\
\hline \multicolumn{11}{|l|}{ Working experience } \\
\hline $2-5$ & 12 & 9.50 & 27 & 21.40 & 46 & 36.50 & 41 & 32.50 & \multirow{5}{*}{17.36} & \multirow{5}{*}{0.14} \\
\hline $6-10$ & 3 & 4.60 & 8 & 12.30 & 28 & 43.10 & 26 & 40.00 & & \\
\hline $11-15$ & 5 & 9.60 & 5 & 9.6 & 24 & 46.20 & 18 & 34.60 & & \\
\hline $16-20$ & 2 & 10.00 & 4 & 20.00 & 7 & 35.00 & 7 & 35.00 & & \\
\hline$>20$ & 4 & 33.30 & 0 & 0.00 & 5 & 41.70 & 3 & 25.00 & & \\
\hline \multicolumn{11}{|l|}{ Additional Training } \\
\hline Yes & 15 & 8.50 & 27 & 15.30 & 73 & 41.50 & 61 & 34.70 & \multirow[t]{2}{*}{1.69} & \multirow[t]{2}{*}{0.64} \\
\hline No & 13 & 11.10 & 17 & 14.50 & 41 & 35.50 & 46 & 39.30 & & \\
\hline \multicolumn{11}{|l|}{ Choice of Modality } \\
\hline Electrotherapy & 26 & 9.30 & 46 & 16.54 & 107 & 34.48 & 99 & 35.61 & \multirow{9}{*}{32.90} & \multirow{9}{*}{0.11} \\
\hline Traction & 13 & 9.02 & 29 & 20.13 & 55 & 38.19 & 47 & 32.64 & & \\
\hline Massage therapy & 25 & 9.32 & 41 & 15.29 & 105 & 39.17 & 97 & 36.19 & & \\
\hline Mckenzie & 16 & 10.06 & 31 & 19.49 & 61 & 38.36 & 51 & 32.08 & & \\
\hline Instruction and advice & 20 & 8.36 & 33 & 13.81 & 99 & 41.42 & 87 & 36.40 & & \\
\hline Back care education & 24 & 8.85 & 44 & 16.23 & 106 & 39.11 & 97 & 35.79 & & \\
\hline Exercise therapy & 24 & 9.16 & 39 & 14.88 & 104 & 39.69 & 95 & 36.25 & & \\
\hline Manipulation therapy & 20 & 11.62 & 24 & 13.95 & 67 & 38.95 & 61 & 35.46 & & \\
\hline Mobilization technique & 19 & 10.32 & 23 & 12.50 & 82 & 44.56 & 60 & 32.61 & & \\
\hline \multicolumn{11}{|c|}{ Use of Outcome Measures } \\
\hline Yes $(221 / 77.3 \%)$ & 20 & 9.00 & 40 & 18.10 & 90 & 40.70 & 71 & 32.10 & \multirow{2}{*}{7.20} & \multirow{2}{*}{0.07} \\
\hline No $(65 / 22.7 \%)$ & 9 & 13.80 & 8 & 12.80 & 18 & 27.70 & 30 & 46.20 & & \\
\hline
\end{tabular}

Two hundred and twenty one (77.3\%) of the respondents made use of outcome measures during the treatment of their patients (table 2). One hundred and seventy-five $(56.30 \%)$ of the respondents said that availability was their reason for the choice of modality. While $196(63.0 \%)$ respondents said they were aware of the availability of LBP treatment guidelines in other parts of the world, only $127(40.8 \%)$ routinely used them (table 3 ). Two hundred and forty-five (78.8\%) opined that there is a need for LBP treatment guidelines in Nigeria; of these, 44 $(18.0 \%)$ were of the opinion that it would encourage better management of LBP (table 3).

\section{DISCUSSION}

It was observed that a majority of the respondents treated patients with low back pain (LBP). This may suggest that LBP is a common reason why patients visit the physiotherapist. This is corroborated by the finding of Jette et al (1994), who in a study on the physiotherapy episode of care for patients with LBP, reported that it was one of the most common problems seen by physiotherapists in outpatient clinics.
Table 3. Frequency Distribution of Respondents' Reasons for Choice of Modality, Awareness, Use of and Need for Low Back Pain Treatment Guidelines in Nigeria (no response $=\mathrm{n} 51,20.8 \%$ )

\begin{tabular}{l|l|l}
\hline Variable & $\begin{array}{l}\text { Frequency } \\
\text { (n) }\end{array}$ & $\begin{array}{l}\text { Percentage } \\
(\%)\end{array}$ \\
\hline Reason for Choice of Modality & & \\
Skill & 241 & 77.50 \\
Availability of modality & 175 & 56.30 \\
Patients's workload & 50 & 16.10 \\
Power outage & 41 & 13.20 \\
\hline Awareness of LBP Treatment & & \\
Guideline & & 63.00 \\
Yes & 196 & 37.00 \\
No & 115 & \\
\hline Use of LBP Treatment Guideline & & \\
Yes & 127 & 40.80 \\
No & 184 & 59.20 \\
\hline Need for the Guideline in Nigeria & & \\
Yes & 245 & 78.80 \\
No & 66 & 21.20 \\
\hline Reasons for the Need & & \\
Best management & 44 & 18.00 \\
Encourages EBP & 22 & 9.00 \\
Uniformity in Management & 19 & 7.80 \\
Best Outcome & 9 & 3.70 \\
Encourages proper diagnosis & 289 & 11.40 \\
Standardized treatment & 34 & 13.90 \\
Quickens recovery & 12 & 4.90 \\
Encourages research & 3 & 1.20 \\
Enhances PT's knowledge & 16 & 6.50 \\
Monitor RX progress & 7 & 2.80 \\
\hline & &
\end{tabular}


The finding that a majority of the respondents discharge their patients after about ten PTS suggests that most of the respondents employed ten treatment sessions for patients with LBP. This finding is in agreement with the trend in the literature. Swinkels et al (2005) reported a mean number of PTS in patients with non-specific LBP to be 9.9 sessions, while Jette et al (1994) reported that episodes of care of patients with LBP consisted of 11 therapy visits (sessions) and extended over 5 weeks.

The finding that there was an association between PTS, gender and age, suggests that gender and age may have an influence on the number of PTS employed by physiotherapists in the treatment of patients with LBP. The finding in this study suggests that older physiotherapists employed fewer treatment sessions in the treatment of patients with LBP than younger physiotherapists. This finding is in agreement with the reports of Hendriks et al (2000) and Swinkels et al (2005), who in separate studies on factors influencing the number of PTS in patients with LBP, reported that older physiotherapists employed fewer treatment sessions than younger physiotherapists. This may be due to their increased skills resulting from experience acquired over the years, more so since the acquisition of additional qualifications in the management of LBP has been reported to influence the number of PTS. Similarly, the finding that male physiotherapists employed fewer treatment sessions than female physiotherapists is in line with the trend in the literature (Hendriks et al, 2000; Swinkels et al, 2005).

This study revealed that there is an association between the educational attainment of the respondents and the number of treatment sessions. Fifty percent of the respondents with an $\mathrm{MSc} / \mathrm{PhD}$ employed less treatment sessions, while a majority of those with only a first degree employed more than 10 treatment sessions. This suggests that the higher the educational level, the less the number of treatment sessions employed. This finding tallies with that of Swinkels et al (2005), who reported that educational level influences the number of treatment sessions. There was an association between areas of interest (specialty) and the number of PTS. The respondents who specialized in orthopaedics employed fewer PTS than others. This finding is corroborated by Swinkels et al (2005).

The finding that there was no significant association between working experience and the number of PTS suggests that working experience may not have a significant influence on the number of PTS, although age was found to have a significant influence on number of PTS. This finding conforms with the findings of Resnik and Hart (2003) and Constance (2000), who also found that there was no significant association between the working experience of physiotherapists and the number of PTS. There was no significant association between the acquisition of additional training (continuous professional development) and the number of PTS. However, there was an association between possessing additional qualifications and the number of PTS, implying that physiotherapists with additional qualifications, particularly in the management of LBP, employed fewer treatment sessions (Resnik and Hart, 2003; Swinkels et al 2005).

There was no significant association between the type of treatment modalities used in the management of LBP patients and the number of PTS. This disagrees with the finding of Battie et al (1994), whose study explaining the attitude and treatment preference of physiotherapists during the management of low back pain revealed that the type of modalities used by the physiotherapist influences the number of treatment sessions employed.

The finding that the majority of the respondents in the present study made use of outcome measures during the treatment of patients with LBP suggests that the use of outcome measures in the treatment of patients with LBP among physiotherapists is a common practice in Nigeria. One possible reason for this may be because pain and functional disability are usually important reasons why patients with LBP will visit the hospital for treatment. These variables are probably assessed and used as measures of improvement for these patients. This finding is in line with the practice of physiotherapists in developed countries like New Zealand, Canada, Scotland, England, United States of America and Australia (Copeland et al, 2008). Akinpelu and Eluchie (2006), in their study exploring the familiarity with, knowledge and utilization of standardized outcome measures among physiotherapists in Nigeria, concluded that the use of outcome measures among physiotherapists in Nigeria is limited. While the present study is specific to the use of outcome measures in the treatment of patients with LBP, the study by Akinpelu and Eluchie was on the general use of outcome measures by physiotherapists in Nigeria. However, the fact that $23 \%$ of the respondents did not use outcome measures in the treatment of patients with LBP still calls for concern, more so, as the use of outcome measures has been reported to have an impact on physiotherapists' intervention and the 
patients' outcome (Copeland et al, 2008). It is therefore recommended that Nigerian physiotherapists should make the use of outcome measures a routine.

A majority of the respondents opined that there is a need to develop LBP treatment guidelines in Nigeria. This, according to them, will standardize the treatment of patients with LBP and encourage proper diagnosis and the use of evidence-based physiotherapy. It has been reported that the main benefit of clinical guidelines is to improve the quality of care of patients (Woolf et al, 1999). As clinical guidelines are usually aimed at increasing the quality of health care provided, it has been found to decrease the number of visits of patients with LBP in the Netherlands. Also, there has been a relatively large change from the use of physical therapy modalities to the use of exercise therapy (Groenendijk et al, 2007).

\section{CONCLUSION AND RECOMMENDATIONS}

Based on the findings of this study, it was concluded that the average number of treatment sessions administered to patients with LBP in Nigeria before they are discharged is ten sessions. Number of physiotherapy treatment sessions was influenced by gender, age, areas of interest and educational attainment. There was a general consensus that a treatment guideline is needed for the proper management of patients with LBP in Nigeria and routine use of outcome measures should be encouraged among the physiotherapists. Specialization should also be encouraged in Nigeria

\section{References}

Akinpelu, A.O. and N.C. Eluchie. 2006. Familiarity with, knowledge and utilization of standardized outcome measures among physiotherapists in Nigeria. Physiotherapy Theory and Practice 22(2): 61-72.

Battie, M, C. Daniel, D.C. Cherkin, A. Richard and R.A. Deyo. 1994. A comparison of physical therapy, chiropractic manipulation, and provision of an educational booklet for the treatment of patients with low back pain. New England Journal of Medicine 339: 1021-1029.

Constance, D.P. 2000. Effect of Experience on Physical Therapist Functional Outcome. Master thesis. St Augustine, Flamingo: University of St Augustine.
Copeland, J.M., W.J. Taylor and S.G. Dean 2008. Factors influencing the use of outcome measure for patients with low back pain: A survey of New Zealand physical therapist. Physical Therapy 88: 1492-1505.

Goldestein, B. 2002. What is back pain? Physical Therapy 68: 123129.

Groenendijk, J.J., I.S. Swinkels, D. Bakker, J. Dekker and C.J. van den Ende 2007. Physical therapy management of low back pain has changed. Health Policy 80: 492-499.

Hendriks, J.M., A.B. Oostendrop, T.M. Bernards, C.D. van Ravensberg, Y.F. Heerkens and R.M. Nelson (2000). The diagnostic process and indication for physiotherapy: A prerequisite for treatment and outcome evaluation. Physical Therapy 86: 14-21.

Hornby, A.S. (2000). Oxford Advanced Learner's Dictionary (6 $6^{\text {th }}$ Edition). Oxford, University Press.

Jette, A.M., K.. Smith, S.M. Heley and K.D. Davis 1994. Physical therapy episode of care for patient with low back pain. Physical Therapy 74: 101-110.

Levin, D.B. (1992). Treatment of Painful Low Back Pain (2 ${ }^{\text {nd }}$ Edition). Philadelphia, Lea and Febigan.

Resnik, L. and D.L. Hart 2003. Using clinical outcome to identify expert physical therapists. In. Mcminn, R.M.. Last's Anatomy: Regional and Applied. ( $9^{\text {th }}$ Edition). New York, Churchill Living Stone. pp 535-540.

Poitras, S., R.. Blais, B. Swaine and M. Rossignol 2005. Management of work-related low back pain; A populationbased survey of physical therapists. Physical Therapy 85: 1168-1181.

Swinkels, C.S., R.H. Wimmers, P.P. Groenewegen, J.H. van den Bosch, J. Dekker and H.M. Ende 2005. What factors explain the number of physical therapy treatment sessions in patient referred with low back pain: A multilevel analysis BioMed Journal 5: 74-76.

Walsh, N.E and R.K.. Schwartz 1990. The influence of prophylactic orthotics on the work place. American Journal of Physical Therapy and Rehabilitation 69: 245-250.

Watson, P., E.M. Hay, R. Mullis, M. Lewis, K. Vohora and C.J.Main 2005. Comparison of physical treatments versus a brief pain-management programme for back pain in primary care: A randomised clinical trial in physiotherapy practice. Lancet 365: 2024-2030.

Woolf, S.H., R .Grol and A. Hutchinson 1999. Clinical guidelines: Potential benefits, limitations and harms of clinical guidelines. BioMed Journal 318: 527-530. 